\title{
Why Ageing is More Important than Being Old
}

Understanding the Elderly in a Mediatized World

\author{
Thorsten Naab \& Christian Schwarzenegger
}

\begin{abstract}
The idea of distinct media generations is frequently discussed in the research literature about elderly media users. This article reviews the theoretical framework of media generations and develops a contrasting perspective that focuses on the dynamics of ageing. Its line of argument is supported empirically based on ten years of longitudinal, representative German national survey data and thirty media biographical interviews. The results indicate the fluidity of generational belonging and the importance of contextual factors to assess elderly's media use. Finally, it is concluded that media dynamics in the lives of the elderly are best examined with a concept of media generations that is not essentially derived from birth - neither of technology, nor of people.
\end{abstract}

Keywords: media generation, elderly, mediatization, media biographies, longitudinal analysis

\section{Introduction}

We are living in an ageing society: Western civilisations are growing older and the elderly constitute an increasing segment of the general population of developed nations and especially within the EU. We are also living in societies, which are characterised by processes of mediatization. Media are permeating almost all areas of social life: private, public, and professional; in the 'far-reaching entanglement of media technologies with the everyday practices of our social world' referred to as 'deep mediatization' (Hepp 2016: 918) they also become inherently relevant for the construction of reality (Couldry \& Hepp 2016). These two observations are at the heart of this article, in which we aim to establish a link between the discourse on the mediatization of society and the complex and changing challenges this poses for the ageing population. We discuss how the elderly are affected by processes of mediatization and how being old changes in relation to the conditions and contexts of ageing. Regarding the old, we ask who they are, what they do with the media, and how media influence their participation in social life. Therefore, we critically review existing research on older adults as audiences and media 
users, especially in terms of evaluating concepts used to differentiate and study media generations. Based on two empirical case studies, we argue that the process of ageing and the contexts of growing old are more important for understanding the elderly in a mediatized world than age as a state. Older adults' media use is rather to be analysed in terms of changes in the media biography than based on categories of 'age'. We argue for a more nuanced approach to media practices of senior citizens - an approach grounded on empirical analyses of older adults' everyday lifeworlds, social networks and communicative bonds, as well as general living conditions beyond media use.

\section{Fantastic elderly and where to find them}

The first challenge of understanding the elderly is to find them and to identify in which contexts they are addressed by existing communication research, and who and how they are depicted to be. Givskov and Deuze (2016:2) elucidate that the concern for later life periods of people within media studies has generally been rendered into research on digital divides (Droguel et al. 2015, Friemel 2016) and on the role of (digital) media in compensating for limitations in health, well-being, and social and financial resources (Laukka 2007, Naab et al. 2013, Richardson et al. 2011). However, the studies leave unclear, who 'older adults' actually are. The understanding varies on a wide age range from somewhat 'over 40' to 'over 75' (Wagner et al. 2010: 870). Being older, elderly, or senior apparently is relative to the contexts of observation. Additionally, older audiences are usually grasped as one group without further differentiation (Lemish \& Nimrod 2015). As Lemish and Nimrod (2015) argue, older audiences are generally addressed as mostly healthy, wealthy, and well-educated people. Treating the elderly as one homogenous group in research, however, is problematic because older people are highly diverse in terms of economic, social, and cultural resources (Givskov \& Deuze 2016). Furthermore, persons with chronic health conditions or dementia, but also immigrants or minorities among the elderly are blanked out as special groups. The same negligence can be concluded for other factors of living, like dwelling in urban or rural areas; having access only to precarious communication environments; being at the peripheral margins of a country or in a cultural and technological centre. While a comprehensive consideration of contextual factors might reduce the importance of age (Jansson \& Andersson 2012), segmenting the current substantial group of mature media users may enhance our understanding of the media practices of the elderly and help avoid misleading generalisations about the population of the elderly in mediatized societies (Lemish \& Nimrod 2015). This is also supported by findings on the digital divide among senior citizens: Friemel (2016) finds an exponential decrease of the likelihood of Internet use with increasing age (Friemel 2016: 328). Hepp, Berg, and Roitsch (2015) similarly show that older media users are the group with the most heterogeneous media use when it comes to community building and bonding with their communicative networks, family, friends, and peers. From various angles, we can thus support the need for differentiation among senior citizens in research. In the following, we discuss concepts of media generations as an approach to this aim. We then propose a more nuanced view that shifts from rather stable and static generations - and 'the old' as a set category - to a more dynamic and process-oriented focus on becoming old and ageing. 


\section{Perspectives on media generations}

In recent years, we can find growing prominence of generations as a construct in audience research and increasing interest in the role of media technologies and mediated communication in the formation and experience of generations (Bolin 2016: 8). Theoretical considerations in this discourse mostly revolve around Mannheim's (1928/1952) seminal work 'The problem of generations' which characterises generations by the interplay between generational site or location (Generationenlagerung); generation as actuality (Generationenzusammenhang), and generation unit (Generationeneinheit). Generational location relates to a person's year of birth and being part of an age group within a specific historical time period. Furthermore, members of generations share the same practical concerns regarding fateful events and crucial historical occurrences, which Mannheim (1928/1952) calls generation as actuality. Considering generation unit, generational belonging is determined by a generation's self-awareness as a community of shared experiences and the self-positioning as a community that can construct collective patterns of orientation and behaviour. Additionally, 'generational experience is formed through fresh contact, and these experiences are held to impact on all later experience' (Bolin 2016: 10). Thus, the first contact to a medium is considered formative for subsequent experiences (Aroldi 2011). Users learn the respective grammar of media during the formative phase of their youth and adolescence. Similar to acquiring language skills, media users appropriate new devices into their lives, but as with learning a foreign language it will always be different from the quasi-natural use of their media mother tongue (Gumpert \& Cathcart 1985). Consequently, Gumpert and Cathcart (1985) elaborate that fresh media experiences which people make throughout their lives might form a stronger intragenerational connector and intergenerational boundary than the chronological order of birth cohorts: media experiences and media's moulding forces for experiences in general are then what binds within generations and separates them from preceding and succeeding ones. However, the idea of distinct media generations emphasises differences between groups of media users. Generations are used as a means of demarcation of social units. Studies on generations commonly emphasise contrasting peculiarities of media user groups, while studies that openly compare different generations and search for intergroup commonalities are rare (Bolin 2014, 2015).

Moreover, empirical studies that make use of generation concepts are often insensitive to differences within generations. Research literature relates the 'birth' of a generation to the emergence, diffusion, and adoption of media technologies; setting the technological features of new media as the benchmark for their use. Media practices that do not exploit the full technological potential are marginally discussed as legitimate forms of media use. Instead concepts of diffusion of technologies understand non-users, late-adopters, or media objectors mainly as obstacles and hindrance for diffusion and thus address non-use or limited use as a condition that needs to be overcome to the end of closing gaps and patch divides (Kaun \& Schwarzenegger 2014). Accordingly, media generations describe groups of media users that are assumed to exploit the potential of media in mainly homogeneous ways and thus participate in shared spaces of experience based on their respective birth cohort and media available at the formative time of youth. These perspectives suggest a strong discontinuity between a generation and its predecessors, as it links the birth of a generation foremost to the emergence of technologies. A formidable example of this understanding is the notion of digital 
natives that implies a significantly different communicative lifestyle - sovereignty in dealing with digital technologies and maximum communicative connectedness - for users born after a certain year (for a differentiated position on digital natives, see Bolin \& Skogerbø 2013).

Although Mannheim's elaborate concept of generations is widely referenced, a major portion of empirical work applies his concept in a way basically reduced to generation location in conjunction with the emergence of media technologies: Statements about media generations are thus often criticised for being too generalising, too deterministic, and for neglecting a life course perspective (Björkin 2015, Bolin 2016, Givskov \& Deuze 2016, Siibak et al. 2014, Westlund \& Weibull 2013). The rather complex theoretical conceptualisation stands in contrast to relatively straightforward empirical measurements referring to birth cohorts only. Within the last 60 years, numerous media innovations, the rise and decline of technologies, and the merging of various communicative functions and needs in convergent devices result in a plethora of diverse media ecologies. Thus, constituting generations as birth cohorts and in conjunction with specific media technologies loses explanatory value, as also potential generations multiply in this regard and last for shorter intervals (for a detailed critique Bolin 2016: 32-34, Hart-Brinson et al. 2016). As Björkin (2015: 54) points out, however, 'it is still useful to use this notion - and, more precisely, generational cohort - as a combination of both location and actuality' in cases where especially quantitative data does not allow further insight into aspects of generational variations. Yet, studies that make use of complementary cultural studies perspectives to acknowledge generational heterogeneities beyond birth cohorts are relatively rare (Siibak et al. 2014). Conversely, individual case studies often miss reflecting their findings with regard to a broader population (Givskov \& Deuze 2016). Finally, perspectives on media generations often neglect that media users' personal biographies are deeply entangled with the experience of social and historical change (ibid). While the media environments in peoples' youth are formative for later life, 'the diversity of biographies related to class and culture, social and geographical mobility, education, work trajectory, exposure to technology and so on' (ibid: 5) result in different media experiences and therefore a different generational formation within the same age group (Hepp et al. 2015, Kortti 2011, Silverstone \& Haddon 1996). Furthermore, although numerous life phases are common for many members of a generation, some life situations are non-linear as they can be entered, left, and re-entered at different points in a person's life course (Bolin 2016: 35-37).

In sum, the aforementioned problems of over-generalisation, causal determinism, and negligence of a life course perspective are symptoms of a rather static understanding of generations within media studies. While birth cohort is used as a main constituent characteristic of media generations, most studies portrait elderly media users mainly as being old and stripped of other peculiar features. Furthermore, studies focus on intergenerational differences from a cross-sectional point of view, although some results indicate the importance of a longitudinal perspective: E.g., while the perceived usefulness of a new technology is identified as the main impediment to new media adoption (Droguel et al. 2015, Melenhorst et al. 2006), it can be argued that previous media experiences might have formed this disposition. Taking all this into consideration, this article suggests overcoming static and stable generations as units of observation, not least since this would enable more attention to important processes of generation formation. 
Working in a similar trajectory, Hepp and colleagues (2015) define media generations as a thickening of one or several age groups of people, who share a specific realm of experience concerning mediatization as well as generational self-understanding based in their media biography. Thereby they overcome an age-based foundation (generation location) in the understanding of generations and invite a process-oriented view. We now elaborate why a focus on the process of generational becoming and of ageing in society allows for a more open observation of the interplay between different media generations and the changes of media ensembles within individual life cycles that shape elderly users' current media practices.

\section{From being old to a process of ageing}

The youngest as well as the oldest people in society are addressed by research in terms of the processes of change that they are going through. The main difference being that the change of the old is reduced to an idea of constantly fading until they finally pass away instead of acknowledging the evolvement of media use during later years (Lemish $\&$ Nimrod 2015). Therefore, we argue that the process-oriented perspective should be both extended (to earlier ages and following across the lifespan and not stopping at a specific age) and intensified (taking the process perspective seriously and study change over time in practices, appropriation, and general orientations also past the inception of 'old age'). This would then allow developing a deeper understanding of the elderly in a mediatized world, their commonalities, and in how far the media practices of elderly users are diversified and plainly individual. Especially a stronger emphasis is needed on how differently the old are ageing in various contexts, under different social and cultural preconditions, and in relation to different social bonds and networks. In his study on the digital divide among senior citizens, Thomas Friemel (2016: 327) concludes that 'the social context seems to influence Internet use in manifold ways'. Major influencers according to his findings are encouragement by personal social networks and previous (every day) experiences and lifeworld contexts. If someone used a computer or the Internet in life before retirement it is much more likely that a person will continue to be an active onliner in later life. Friemel's findings also stimulate a focus on inter- and transgenerational conversations for the importance of media appropriation, because senior citizens stated it was most likely that they would find it attractive to learn Internet use from friends and families. An interview study with seniors aged between 71 and 92 years comes to similar conclusions (Wangler 2015): Personal motivation and the promise of personal benefits are crucial for old agers to acquire new technological skills and to appropriate new media (devices) in their media repertoire. Given the perspective of a proper return, older adults are still open and willing to invest in acquiring new media competencies.

\section{Research questions and research strategy}

We discussed that the differences and how media use evolves within the elderly segments of the population are overlooked or trivialised by research while, in fact, the group is highly heterogeneous and diversified in terms of media practices and contextual factors. Our article's empirical perspective takes up on this idea. We present the results of two 
analyses to substantiate our argument to switch focus from what the old do with the media once they are old to the dynamics and processes of ageing (with the media), and how transitory media use is over the lifespan. We address the following research questions:

RQ1: Do elderly media users belonging to different media generations defined as a combination of generation as location and generation as actuality use different media?

RQ2: How much does an operationalisation of generation as combination of location and actuality coincide empirically with an operationalisation of generation as unit?

RQ3: How mutable is elderly's affiliation with a specific generation over time?

Study 1 illustrates the shortcomings of current operationalisations of media generations as well as it points out the limits of available longitudinal data. Therefore, the study investigates and compares older people's media use based on secondary data from a longitudinal, representative German national survey. It shows that the common operationalisation of generation as combination of location and actuality has only minor predictive power with regard to elderly's media use (RQ1). Furthermore, the study demonstrates the limits of quantitative data by comparing the empirical overlap of different generation operationalisations (RQ2). Finally, Study 1 attempts to give a first impression about the fluidity of generational belonging over the course of time (RQ3).

Study 2 inspects media practices on the microscopic level of media biographies with people from different age cohorts. It contrasts formative practices in the youth with processes of ageing throughout different life stages to examine the generational inhomogeneity with regard to the appropriation and subjective meaning over the lifespan (RQ3).

\section{Study 1}

\section{Method}

Design. The study conducts a secondary analysis of the Media Analysis dataset (MA) (Hagenah \& Meulemann 2006: 7-12). The MA accumulates yearly representative surveys on German residents' media use together with demographic and lifestyle variables. The current study draws on data from the MA surveys from the years 2000 to 2009. The spread of the Internet and the according home computer use have drastically changed the electronic media landscape during these years. The respective period of time is long enough to investigate elderly media users' adoption of digital media and its effect on electronic media use. Additionally, a methodological argument speaks in favour of limiting the analysis to this time period: Since 2000, the measures and the inquiry mode of the surveys have been stable (Hagenah \& Meulemann 2006), which is a major requirement to longitudinal analyses.

Subjects. MA surveys between 2000 and 2009 include data from 194,117 German citizens that were born before 1962 and experienced the introduction of radio or TV during their childhood or adolescence. Fifty-five percent of the respondents were female. The average age was 60.64 years $(\mathrm{SD}=11.19)$. Regarding formal education, $56.4 \%$ completed German main school (grade 9), 27.7\% completed intermediate school (grade 10 ), and $16.0 \%$ completed college preparation school (at least grade 12). 
Generation as combination of location and actuality. Generation as combination of location and actuality is a common operationalisation of media users' generational belongings. This is often implemented with a deliberative choice of birth cohorts based on assumed formative media settings in media users' youth (Bolin 2016), despite that it flattens the perspective on media generations since generation as actuality is projected onto generation as location. However, we follow this reductive operationalisation in order to demonstrate the problems of Björkin's (2015) suggestion of the use of data that allow no further insight into generations. Considering electronic media use, two generations of elderly media users are of particular importance: The radio generation consists of participants that passed their childhood between 1930 and 1950 (Falkenberg 2005). After developing into a mass medium in the 1930 s, the radio was the dominant electronic medium until the 1950s. The monochrome TV generation experienced the rise of television. Television can be considered a mass medium in Germany only since the end of the 1950s. Thus, this generation incorporates participants born between 1950 and 1962 (before the start of colour television in 1963). Table 1 shows that the share of radio generation members decreases from $66 \%$ in the year 2000 to $62 \%$ in the year 2009 . Members of the radio generation are on average 67.4 years old (compared to 48.7 years on average of the monochrome TV generation). Furthermore, they are lower educated than members of the monochrome TV generation. This finding can be explained by the fact that Germany's educational expansion in the 1960s (Friebel 2008) had only limited effects on children born before the late 1950s.

Table 1. Sociodemographic characteristics of radio generation, TV generation, and general population

\begin{tabular}{lccc}
\hline & $\begin{array}{c}\text { radio generation } \\
(\mathrm{n}=123,587)\end{array}$ & $\begin{array}{c}\text { TV generation } \\
(\mathrm{n}=70,522)\end{array}$ & $\begin{array}{c}\text { total } \\
(\mathrm{N}=194,117)\end{array}$ \\
\hline$\varnothing$ Age in years & 67.4 & 48.7 & 60.6 \\
Percentage of women & 54.5 & 54.8 & 54.6 \\
Education (in \%) & & & \\
$\quad$ main school & 65.9 & 39.7 & 56.4 \\
intermediate school & 20.6 & 40.0 & 27.8 \\
college preparation school & 13.5 & 20.3 & 16.0 \\
Employment (in \%) & & & \\
$\quad$ working & 14.1 & 76.5 & 36.8 \\
not part of the labour market & 6.1 & 10.5 & 7.7 \\
retired & 77.7 & 3.5 & 50.7 \\
other & 2.1 & 9.5 & 4.8 \\
\hline
\end{tabular}

Note: $\mathrm{N}=194,117$

Generation as unit and electronic media use. The MA conducts self-reports of respondents' use of different electronic media between 5:00 am and 12:00 pm on the day before the inquiry. Data are acquired on quarter-hourly basis and include 'listening to CD/ cassette/MP3', 'radio listening', 'watching TV', 'watching video/DVD', and 'dealing with PC'. All scales range from zero minutes to 1,140 minutes of media use. Table 2 gives an overview of the average usage of the media devices in the sample. We use those variables in two different ways: Considering the test of whether the affiliation to a 
specific generation based on the combination of location and actuality leads to different media use (RQ1), the aforementioned variables functioned as dependent variables within a general linear model. With regard to the investigation of the empirical overlapping of generation as location and actuality with generation as unit (RQ2), we will reveal groups of respondents similar in their use of electronic media by cluster analysis. Since the available data give no insight into possible social practices of historical, concrete social groups, we use these clusters as a proxy for shared media experience, i.e. as generations as unit.

\section{Results}

Generation as location and actuality as a predictor of electronic media use. A general linear model (Table 2) showed that the radio generation and the monochrome TV generation significantly differ with regard to their use of electronic media (part. $\operatorname{Eta}^{2}=.058$; Wilk's Lambda $=.942, \mathrm{df}=194,111, \mathrm{p}<.001$ ). While the monochrome TV generation is characterised by a comparable higher use of all electronic media except watching television, it appears that generational belonging especially explains differences in 'watching television' (part. $\mathrm{Eta}^{2}=.020, \mathrm{~F}=4,029.134$, $\mathrm{df}=194,116, \mathrm{p}<.001$ ) and 'PC use' (part. $\left.\mathrm{Eta}^{2}=.032, \mathrm{~F}=6,391.716, \mathrm{df}=194,116, \mathrm{p}<.001\right)$. It seems reasonable that members of the radio generation use their TV during the day, while members of the monochrome TV generation might commit to PC use at work.

Table 2. Use of electronic media by generational belonging

\begin{tabular}{lccc}
\hline & $\begin{array}{c}\text { radio generation } \\
(\mathrm{n}=123,587)\end{array}$ & $\begin{array}{c}\text { TV generation } \\
(\mathrm{M}=70,522)\end{array}$ & $\begin{array}{c}\text { total } \\
(\mathrm{N}=194,117)\end{array}$ \\
& $(\mathrm{SD})$ & $\mathrm{M}$ & $\mathrm{M}$ \\
& 183,50 & $(\mathrm{SD})$ & 196,59 \\
\hline Radio listening $^{1,2}$ & $(195,10)$ & $(227,52$ & $(208,21)$ \\
& 11,16 & 22,52 & 5,29 \\
Listening to CD/cassette/MP3 & $(52,76)$ & $(76,68)$ & $(62,76)$ \\
& 232,19 & 183,69 & 214,57 \\
Watching TV & $(163,58)$ & $(157,11)$ & $(163,58)$ \\
& 1,22 & 2,44 & 1,67 \\
Watching video/DVD & $(14,04)$ & $(21,22)$ & $(17,01)$ \\
& 19,06 & 63,39 & 35,17 \\
Dealing with $\mathrm{PC}^{1,6}$ & $(84,43)$ & $(159,69)$ & $(119,40)$ \\
& & & \\
\hline
\end{tabular}

Note: $\mathrm{N}=194,117$

Partial Eta ${ }^{2}=.058$, Wilk's Lambda $=.942, \mathrm{p}<.001, \mathrm{df}=194,111$

${ }^{1}$ Minutes used between 5:00 am and 12:00 pm, requested quarter-hourly for the day before inquiry

2. Partial $\mathrm{Eta}^{2}=.007, \mathrm{~F}=1,352.901, \mathrm{p}<.001, \mathrm{df}=194,116$

3. Partial $\mathrm{Eta}^{2}=.008, \mathrm{~F}=1,482.627, \mathrm{p}<.001, \mathrm{df}=194,116$

4. Partial $\mathrm{Eta}^{2}=.020, \mathrm{~F}=4,029.134, \mathrm{p}<.001, \mathrm{df}=194,116$

5. Partial $\mathrm{Eta}^{2}=.001, \mathrm{~F}=231.699, \mathrm{p}<.001, \mathrm{df}=194,116$

6. Partial $\mathrm{Eta}^{2}=.032, \mathrm{~F}=6,391.716, \mathrm{p}<.001, \mathrm{df}=194,116$ 
Generation as unit. To pool respondents who share similar media use experiences to a group, a cluster analytical approach was chosen. Since respondents who differ in their media use are clustered in different groups, the clusters show different patterns of media use. The conducted hierarchical agglomerative cluster analysis and a subsequent $\mathrm{k}$-means clustering revealed four distinct groups (Table 3): While listening to the radio and watching television is important for all elderly (as shown by the high usage means of these devices compared to the other devices), the first cluster aggregates those recipients who are notably attached to the radio. Similar clusters can be found with regard to watching television ('TV watchers') and PC use ('PC users'). Finally, the 'non-devoted' media users can be characterised as having little interest in electronic media compared to the average population.

Table 3. Mean ratings for the four clusters of media generations as unit of electronic media use

\begin{tabular}{lrrrrrr}
\hline & $\begin{array}{c}\text { Radio } \\
\text { listeners }\end{array}$ & $\begin{array}{c}\text { TV } \\
\text { watchers }\end{array}$ & $\begin{array}{c}\text { PC } \\
\text { users }\end{array}$ & $\begin{array}{c}\text { Non- } \\
\text { devoted }\end{array}$ & \multicolumn{1}{c}{$\mathrm{F}$} & $\mathrm{p}<$ \\
\hline Radio listening $^{1}$ & $517^{\mathrm{a}}$ & $116^{\mathrm{b}}$ & $191^{\mathrm{c}}$ & $96^{\mathrm{d}}$ & $128,284.97$ & .000 \\
Listening to CD/cassette/MP3 $^{1}$ & $12^{\mathrm{a}}$ & $8^{\mathrm{b}}$ & $23^{\mathrm{c}}$ & $20^{\mathrm{d}}$ & 461.81 & .000 \\
Watching TV $^{1}$ & $184^{\mathrm{a}}$ & $424^{\mathrm{b}}$ & $145^{\mathrm{c}}$ & $131^{\mathrm{d}}$ & $77,479.78$ & .000 \\
Watching video/DVD $^{1}$ & $1^{\mathrm{a}}$ & $1^{\mathrm{a}}$ & $3^{\mathrm{b}}$ & $2^{\mathrm{c}}$ & 40.52 & .000 \\
Dealing with PC $^{1}$ & $14^{\mathrm{a}}$ & $9^{\mathrm{b}}$ & $513^{\mathrm{c}}$ & $11^{\mathrm{d}}$ & $272,080.69$ & .000 \\
\hline
\end{tabular}

Note: $\mathrm{N}=194,117$

1. Minutes used between 5:00 am and 12:00 pm, requested quarter-hourly for the day before inquiry

abc. Correspond to significant differences $(\mathrm{p} \leq .001)$ between the clusters in Tamhane $\mathrm{T} 2$ posthoc comparisons

Overlap of generation as combination of location and actuality with generation as unit. Crosstabs show the overlap as well as the differences in classification of elderly between generation as combination of location and actuality and generation as unit. The radio and the TV generation have similar shares of 'non-devoted' media users ( $48.9 \%$ compared to $49.4 \%)$ and 'radio users' $(20.2 \%$ compared to $24.2 \%)$. Since the two generations actually show similar patterns of use instead of differences, a reliance on the traditional generation concept would lead to a wrongful expectation of discrepancies. Higher differences occur with regard to 'TV watchers' (28.6 \% compared to $17.2 \%)$ and 'PC users' ( $2.3 \%$ compared to $9.1 \%$ ). When coming from a classic understanding of generations as location and actuality, this must be surprising: The so-called TV generation stands out due to its use of low TV use. Either this generation's living circumstances inhibit intensive TV use or they have already moved on to PC use as compared to the sample average.

This pattern becomes even more apparent when we investigate the shift of the radio and TV generation over time. While the share of 'PC users' increases in both generations, its growth is significantly bigger within the monochrome TV generation than it is within the radio generation (Figure 1). 


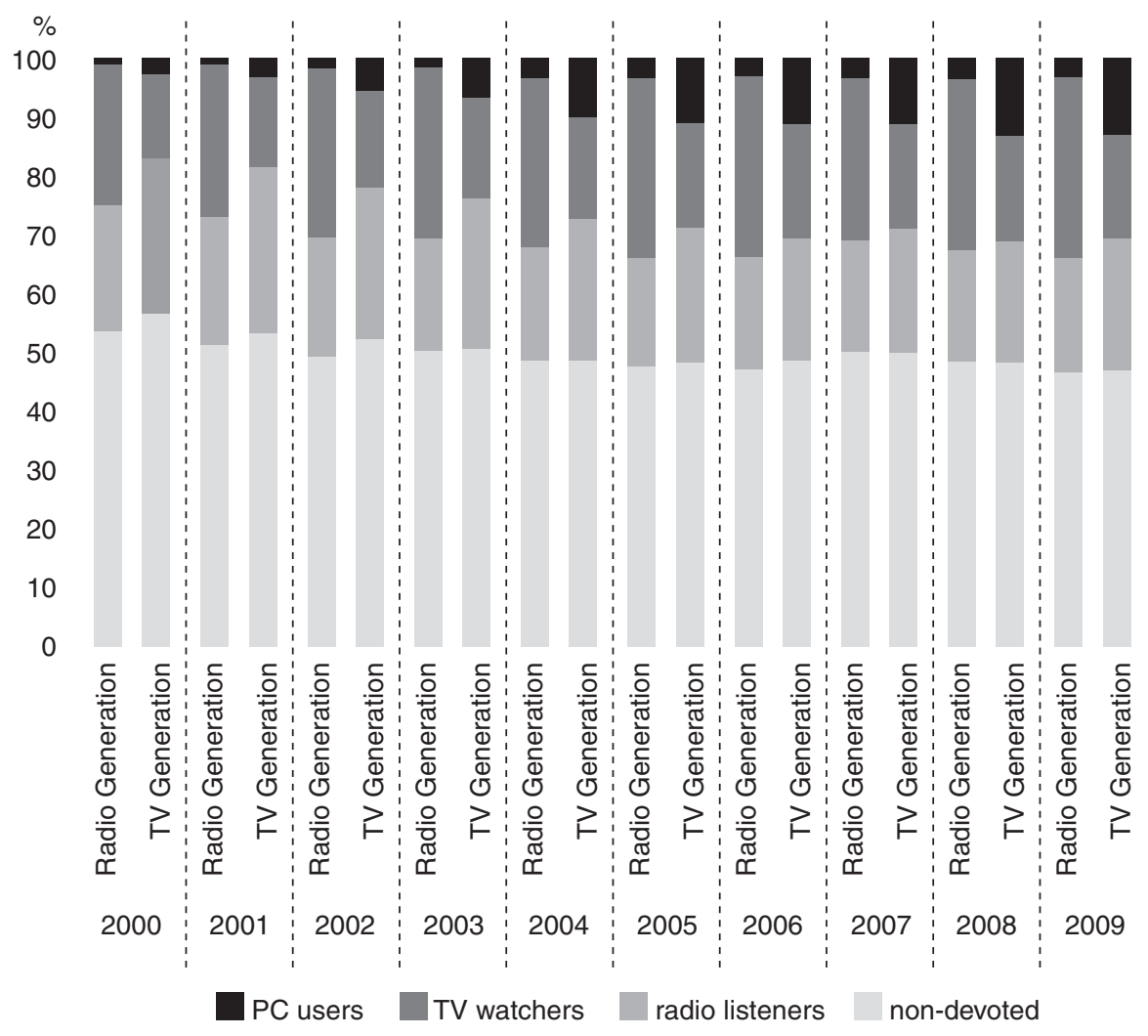

Figure 1. Generational belonging as unit by generational belonging as location and actuality over time

\section{Study 2}

The second study focuses on media biographies of three different age groups. It was considered vital for the study to not focus only on elderly, young, or middle-aged users in mutual separation, but to address their everyday media practices and media routines in a way that would allow a perspective on shifting media repertoires, practices in different life stages, and the interplay of generations within the family and beyond (RQ3).

\section{Method}

Media biographies combine a variety of data collecting strategies about media practices in different stages of the life cycle. Foremost, they are based on biographical interviews. They are an invaluable method for approaching media use in the lifeworld and how it changes over time. The media biographies addressed different life stages for all of the participants and were coded for:

- stability and change of 'generation units' in the life course

- patterns of media use in the family and with social peers

- nostalgia for media technologies and the anxiety for cherished technologies to disappear 
- locating personal media practices in comparison to younger and older cohorts as well as to people of the same age (generational self-positioning)

- upheavals in the biography and life events important for changes in media use (coming-of-age, first own household, caesura in professional life, marriage, children, divorce, retirement).

Nevertheless, the challenge of doing such interviews is to address everyday practices and routines in the context of the lifeworld of users, without overstating exceptional and peculiar media rituals or genre preferences, as this would emphasise the outstanding and not necessarily the ordinariness of mundane media use (Dhoest 2015, Schwarzenegger $\&$ Naab 2016). Media-centrism of biographical interviews can also result in overstating the relevance of media for life in general or for particular periods of life (Aufenanger 2006, Kübler 1982, Vollbrecht 2009). Finally, biographical interviews must be used with caution as personal memories reconstruct the past through representation and link it to what happened.

\section{Results}

Media biographies provide an exhausting richness on insights in media practices. We will only cursory reflect a selection of particular findings in light of the bigger argument made in this article. The media biographies substantiate the theoretical argument that contextual factors are important for media appropriation and patterns of media use in the formative period of the youth but also remain so in later life. This is best illustrated by Ernst Wagner. Aged 60, he works as a long distance bus driver. Radio is an essential medium in his professional life in uncounted hours on the road and away from home. Although age-wise a member of the television generation, TV has always been a secondary yet special medium in his life. Since the 1980s, he has always tried to catch up with technological developments: He appreciated a well-equipped home cinema system with means for time flexible use, and thus was as an early adopter for video-recorders in his neighbourhood. He had never used a computer before his mid-fifties; but after both of his children moved to other countries he has started to email and he has also intensified his skills in using the smartphone to share photographs via personal messenger services. He also increasingly discovers the joy of games on the device. Ernst leads strictly separate media lives depending on whether he is at home or in motion. His media repertoire is growing in his later life due to life events and personal circumstances. Different but similar is the case of Marie Grell. Being 79 years old, her biography is an example of a member of the radio generation ageing with media and integrating new media into her routines. Having grown up in a small town in rural Germany, for her it has always been important to live autonomously and independently. While in younger years media were important for her in terms of radio and good hi-fi equipment, connecting with the world has always been the driving force to acquire new technologies. Married to a musician, she always lived an audiophile life, also in her media preferences. In her seventies, she is still very open and ambitious to learn, and while the radio is still her dominant medium (one device in every room), she makes experiences with the Internet. Owning her first laptop only as a pensioner, and learning how to use it with the help of her children and grandchildren, she appreciates quick and comprehensive news and encyclopaedic infor- 
mation online but has reservations against the perceived risks of all kinds of financial transactions and the ubiquity of smartphones.

The cases of Ernst and Marie show that media use still continues to change and evolve past a certain age. For understanding the elderly in mediatized worlds it is thus inevitable to study how people become old, but also to study changes in their media use when they are old already.

We can also learn that the appropriation of new technologies does not necessarily hint to practices and patterns of use or that new devices' technological potentials will be exploited: Uwe Schorn (58) is 'quite up to date' in terms of the technologies he uses, but he only buys new devices when an older one is broken. He replaces technology one by one, using it for exactly the same functions as he used the previous model, regardless of technological progress and new features that could be activated - patterns of use and media functions are more stable (also across generations) than the technologies used for them.

In terms of a generational awareness or self-positioning as generation, our findings were quite interesting. The informants in all age groups clearly used generational ideas for the distinction between themselves and older or younger cohorts, assuming changed patterns of media use. They were, however, well aware of intragenerational differences and explained that media use in the same age group 'clearly depends' on life circumstances (e.g. young parents use media less than people of the same age without kids). Moreover, they suppose that they might have more in common with individuals from other age groups than within their own. These findings are in line with the processoriented definition of media generations by Hepp et. al. (2015), and used in the above - seeing generations as thickenings of people sharing a realm of experiences related to and with media.

\section{Discussion and conclusion}

The main aim of this article was to reconsider the approach of media and communication research on elderly media users. It substantiated the claim to understand media generations in the sense of ageing as an ongoing process rather than in the sense of the completed status of being old. Thus, the literature review carved out that current research on elderly media users exhibits an insufficiently refined form of reasoning. The explanation for this shortcoming might be found in media scholars' focus on the concept of generations. While the generational argument is substantially helpful to understand the formation of user collectives that withstand the test of time, it also seems to inveigle researchers to centre their attention largely on the comparison and demarcation of groups in the sense of generation as location and generation as actuality. Therefore, the present article suggests a stronger recourse to the more comprehensive perspective of Mannheim's concept of generations in order to understand being old as the effect of ageing. The two studies presented in this article illuminate this general thought: The results of Study 1 illustrate the fluidity of generational belonging in two ways. First, the conducted analysis indicates that the commonly applied measurement of generational belonging based on generation as location and actuality has only marginal explanatory power with regard to generation specific use of electronic media. The subsequent cluster analysis empirically pools groups of people who share similar media use, thus revealing 
media generations based on generation as unit. However, these clusters are not congruent with the generations as a combination of location and actuality. Instead, the comparison of both measurements indicates that the radio generation and the monochrome TV generation share a large proportion of the same clusters. This result partly contradicts the assumption that both generations are solely realisations of different structures of media use opportunities, being the monochrome TV generation still working and the radio generation already being retired. Instead, it can be argued that the generation as unit implicitly takes individual life circumstances into account which leads to a more differentiated perspective on elderly media users. Furthermore, as we used rather general indicators of media experience, we suppose that a further differentiation of elderly media users might manifest on a less abstract level of people's media use, e.g. selection of a specific program, competences and skills, tastes, motivations, rituals of usage, incorporation of media contents. Finally, our analysis demonstrates the changing of sub-generation composition within the radio generation and the monochrome TV generation over time due to a changing media environment. This argument is further stressed by Study 2. Its results explicate the importance of generations' previous media experiences and practices as well as a generation's previous life stages as the key to encode and understand current media behaviour. Furthermore, the investigated media biographies underline that ageing goes beyond being old by actively forming and transforming a stunningly diverse ecology of elderly media users within a mediatized world. Consequently, considering the methodological approaches to elderly media users, this article follows the demand of comprehensive research that complements the perspective of cultural studies and media studies with quantitative audience research (e.g. Siibak et al. 2014). Moreover, instead of cohort and technology centrism, research on media generations needs to bear in mind the significance of the processual character of both mediatization and ageing: 'Generationing' (Siibak \& Vittadini 2012) is primarily determined by the dynamic of continuities and changes after the formative years in individuals' media biographies. Finally, this might mean to recalibrate the lens of (historical) audience research. Rather than arguing from the view of a grown media offering, media scholars pay more attention to research that explains audience ecologies based on the interplay of different media users' biographies.

\section{References}

Aroldi, Piermarco (2011). Generational Belonging Between Media Audiences and ICT Users, pp. 51-68 in Colombo, Fausto \& Fortunati, Leopoldina (eds.) Broadband Society and Generational Changes. Frankfurt am Main: Peter Lang.

Aufenanger, Stefan (2006). Medienbiographische Forschung [Media Biographic Research], pp. 515-525 in Krüger, Heinz-Hermann \& Marotzki, Winfried (eds.) Handbuch erziehungswissenschaftliche Biographieforschung. Wiesbaden: VS Verlag für Sozialwissenschaften.

Björkin, Mats (2015). Reconstructing Past Media Ecologies: The 1960s Generation in Sweden. European Journal of Communication, 30(1): 50-63.

Bolin, Göran (2014). Media Generations: Objective and Subjective Media Landscapes and Nostalgia among Generations of Media Users. Participations. Journal of Audience \& Reception Studies, 11(2): 108-131.

Bolin, Göran (2015). Passion and Nostalgia in Generational Media Experiences. European Journal of Cultural Studies. Advance online publication: http://doi.org/10.1177/1367549415609327

Bolin, Göran (2016). Media Generations: Experience, Identity and Mediatised Social Change. London: Routledge.

Bolin, Göran, \& Skogerbø, Eli (2013). Age, Generation and the Media. Northern Lights: Film \& Media Studies Yearbook, 11(1): 3-14. 
Couldry, Nick, \& Hepp, Andreas (2016). The Mediated Construction of Reality: Society, Culture, Mediatization. Cambridge: Polity.

Dhoest, Alexander (2015). Audience Retrospection as a Source of Historiography: Oral history Interviews on Early Television Experiences. European Journal of Communication, 30(1): 64-78.

Droguel, Leyla; Joeckel, Sven \& Bowman, Nicholas D. (2015). The Use and Acceptance of New Media Entertainment Technology by Elderly Users. Development of an Expanded Technology Acceptance Model. Behaviour \& Information Technology, 43(11): 1052-1063.

Falkenberg, Karin (2005). Radiohörer. Zu einer Bewußtseinsgeschichte 1933 bis 1950 [Radio Listeners. A History of Consciousness 1933 to 1950]. Haßfurt: Hans Falkenberg.

Friebel, Harry (2008). The Children of the Educational Expansion Era in Germany: Education and Further Training Participation in the Life-course. British Journal of Sociology of Education, 29(5): 479-492.

Friemel, Thomas N. (2016). The Digital Divide has Grown Old: Determinants of a Digital Divide among Seniors. New Media \& Society, 18(2): 313-331.

Givskov, Cecilie, \& Deuze, Mark (2016). Researching New Media and Social Diversity in Later Life. New Media \& Society. Advance online publication: http://doi.org/10.1177/1461444816663949

Gumpert, Gary \& Cathcart, Robert (1985). Media Grammars, Generations, and Media gaps. Critical Studies in Mass Communication, 2(1): 23-35.

Hagenah, Jörg, \& Meulemann, Heiner (eds.) (2006). Sozialer Wandel und Mediennutzung in der Bundesrepublik Deutschland [Social Change and the Media Use in the Federal Republic of Germany]. Berlin: Lit.

Hart-Brinson, Peter; Yang, Guobin \& Aroldi, Piermarco (2016). Techno-Social Generations and Communication Research, pp. 91-106 in Nussbaum, Jon. F (ed.), Communication Across the Life Span. New York, NY: Peter Lang.

Hepp, Andreas (2016). Pioneer Communities: Collective Actors in Deep Mediatisation. Media, Culture \& Society, 38(6): 918-933.

Hepp, Andreas; Berg, Matthias \& Roitsch, Cindy (2015). Mediengeneration als Prozess [Media Generation as a Process]. Medien \& Altern, no Vol. (6): 19-33.

Jansson, André \& Andersson, Magnus (2012). Mediatization at the Margins: Cosmopolitanism, Network Capital and Spatial Transformation in Rural Sweden. Communications, 37(2), 173-194.

Kaun, Anne \& Schwarzenegger, Christian (2014). No Media, Less Life? Online Disconnection in Mediatized Worlds. First Monday, 19(11), online only publication: http://doi.org/10.5210/fm.v19i11.5497

Kortti, Jukka (2011). Multidimensional Social History of Television: Social uses of Finnish Television from the 1950s to the 2000s. Television \& New Media, 12(4): 293-313.

Kübler, Hans-Dieter (1982). Medienbiographien - ein neuer Ansatz der Rezeptionsforschung? [Media Biographies - a New Approach in Reception Studies?] Medien + Erziehung, 26(4): 194-205.

Laukka, Petri (2007). Uses of Music and Psychological Well-Being among the Elderly. Journal of Happiness Studies, 8(2): 215-241.

Lemish, Dafna, \& Nimrod, Galit (2015). From the Womb to the Tomb: Conceptual Similarities in Studying the Youngest and the Oldest of Audiences, pp. 145-158 in Zeller, Frauke; Ponte, Christina \& O'Neill, Brian (eds.) Revitalising Audience Research: Innovations in European Audience Research. Retrieved from http://public.eblib.com/choice/PublicFullRecord.aspx?p=1826778 (accessed 2017-01-13)

Mannheim Karl (1928/1952). The Problems of Generations, pp. 276-322 in Kecskemeti, Paul (ed.) Karl Mannheim: Essays. London: Routledge.

Melenhorst, Anne-Sophie; Rogers, Wendy A. \& Bouwhuis, Don G. (2006). Older Adults' Motivated Choice for Technological Innovation: Evidence for Benefit-Driven Selectivity. Psychology and Aging, 21(1): 190-195.

Naab, Thorsten; Scherer, Helmut; Emde, Katharina; Dyszy, Agnes; Engel, Stefanie \& Sponer, Julia (2013). Vertrautheit und Gewohnheit: Die Rolle der Mediennutzung in Senioreneinrichtungen [Familiarity and Habit: The Role of Media Use in Retirement Homes]. Medien \& Altern, 2(3): 46-60.

Richardson, Margaret; Zorn, Theodore E. \& Weaver, Kay (2011). Older People and New Communication Technologies Narratives from the Literature. Annals of the International Communication Association, 35(1): 121-152.

Schwarzenegger, Christian \& Naab, Thorsten (2016). Neue Vielfalt und Mediengenerationen. Ein Beitrag zur historischen Mediennutzungsforschung? [New Diversity and Media Generations. A Contribution to Historical Audience Research?], pp. 255-280 in Birkner, Thomas; Löblich, Maria; Tiews, Alina Laura \& Wagner, Hans-Ulrich (eds.) Neue Vielfalt: Medienpluralität und-konkurrenz in historischer Perspektive. Köln: Herbert von Halem.

Siibak, Andra \& Vittadini, Nicoletta (2012). Introducing Four Empirical Examples of the 'Generationing' Process. Cyberpsychology: Journal of Psychosocial Research on Cyberspace, 6(2), article 1. doi: $10.5817 / \mathrm{CP} 201221$ 
Siibak, Andra; Vittadini, Nicoletta \& Nimrod, Galit (2014). Generations as Media Audiences: An Introduction. Participations. Journal of Audience \& Reception Studies, 11(2): 100-107.

Silverstone, Roger \& Haddon, Leslie (1996). Information and Communication Technologies and the Young Elderly. A Report on the ESRC/PICT study on the Household and Information and Communication Technologies. Falmer: University of Sussex.

Vollbrecht, Ralf (2009). Der medienbiographische Ansatz in der Altersmedienforschung [The Media Biographic Approach in the Research on Elderly and Media], pp. 21-30 in Schorb, Bernd; Hartung, Anja \& Reißmann, Wolfgang (Eds.) Medien und höheres Lebensalter. Wiesbaden: VS.

Wagner, Nicole; Hassanein, Khaled \& Head, Milena (2010). Computer Use by Older Adults: A Multi-Disciplinary Review. Computers in Human Behavior, 26(5): 870-882.

Wangler, Julian (2015). (K)Eine Frage der Generation. Eine empirische Untersuchung zur Aneignung neuer Medien im höheren Lebensalter [(No) Question of Generation. An Empirical Study on the Adoption of New Media in Later Life Stages]. Medien \& Altern, 4(6): 64-75.

Westlund, Oscar \& Weibull, Lennart (2013). Generation, Life Course and News Media Use in Sweden 19862011. Northern Lights: Film \& Media Studies Yearbook, 11(1): 147-173. 